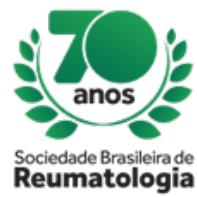

\title{
ATYPICAL KAWASAKI CLINICAL CASE
}

Rogério do Prado (Hospital Municipal Carmino Caricchio, São Paulo, SP, Brasil), Priscila Porto de Almeida Nogueira (Hospital Municipal Carmino Caricchio, São Paulo, SP, Brasil), Caroline Carone (Hospital Municipal Carmino Caricchio, São Paulo, SP, Brasil), Lara Pignata de Oliveira (Hospital Municipal Carmino Caricchio, São Paulo, SP, Brasil), Gabriela Procópio de Almeida Nogueira (Hospital Municipal Carmino Caricchio, São Paulo, SP, Brasil), Soraia Sekkar Pádua (Hospital Municipal Carmino Caricchio, São Paulo, SP, Brasil)

\section{BACKGROUND}

Incomplete or atypical Kawasaki disease includes patients who do not meet all criteria for classical disease. It is common in children under 12 months of age and is characterized by unexplained fever lasting more than or equal to 5 days associated with two or three classic clinical criteria. In these cases a laboratory evaluation and echocardiogram are recommended and in the presence of evidence of systemic inflammation the diagnosis of incomplete disease may be established in the presence of three or more of the following criteria: Albumin lower $3 \mathrm{~g} / \mathrm{dL}$, anemia, elevation of alanine aminotransferase platelets after the seven days greater 450000 / mm3, greater leukocytes 15000 / mm3, greater urine 10 leukocytes / field of large magnification.

\section{CASE REPORT}

Patient GKJM, aged 1 year and 8 months, started fever associated with lip hyperemia and bilateral conjunctival hyperemia, after two days with persistence of fever, started hyperemic plaques in the trunk, upper limbs and face. On the following day, the patient had vomiting, bilaterally palpable submandibular lymphnodes measuring at least $1 \mathrm{~cm}$ with hyperemic plaques on the face and trunk, oropharyngeal hyperemia, with scaling of the genital region. On the 5th day of the disease, the patient developed worsening of the skin lesions with confluence and elevation of the plaques, which disappeared at the finger-pressure and significant edema of the hands, feet and testicles. He presented improvement of the conjunctival and oropharynx hyperemia with labial desquamation without further episodes of vomiting, maintaining febrile condition. Laboratory tests: normocytic anemia, thrombocytopenia, increased inflammatory tests, liver enzymes and DLH, albuminemia, without leukocyte alterations. Echocardiogram was performed without alterations. Immunoglobulin $2 \mathrm{mg} / \mathrm{kg}$ was performed, with significant improvement of lesions, general condition and edema regression. 48 hours after the immunoglobulin ASA was satarting at a dose of $40 \mathrm{mg} / \mathrm{kg} /$ day. On the 12 th day of the patient's illness, he had platelet count, normalization of inflammatory tests and liver enzymes, accompanied by desquamation of the hands and feet. Patient was discharged from ASA with outpatient follow-up. So far, he had no echocardiogram changes and there was no recurrence of the condition.

\section{CONCLUSION}

The diagnosis of incomplete Kawasaki is considered of extreme importance, since the late treatment implies sequels that reflect on the adult's quality of life health later. 